The purpose of this study was to investigate characteristics of injury among Iranian elite female volleyball players. Seventy-four players from five teams which participated in 2006-2007 Iran female volleyball leagues were studied. The information related to injury were collected using injury report form that completed by teams physicians. Descriptive statistics and $\chi^{2}$ test were used for analyses of data. In total 49 injuries was noted that $77.8 \%$ of them occurred in lower extremities and $18.5 \%$ in upper extremities and $3.7 \%$ in trunk. Most common sites of injury were ankle $(51.8 \%)$ and knee $(22.2 \%)$. Most common type of injuries was sprain $(55.6 \%)$ and strain $(18.5 \%)$. The majority of injuries were occurred in spiker $(55.6 \%)$, setters $(25.9 \%)$ and libero $(18.5 \%)\left(\chi^{2}=10.93, p<0.05\right)$. Spikers injured mostly in ankle and knee, setters in fingers and libero in wrist. There was no difference between contact and non-contact injuries $\left(\chi^{2}=1, p>0.05\right)$. Rate of injuries during practice were significantly more than competition $\left(\chi^{2}=5.89, p<0.05\right)$. Most of injuries were occurred because of landing from jumping. Rate of injuries that occurred in front line position were significantly higher than back line position $\left(\chi^{2}=5.81, p<0.05\right)$. In conclusion, spikers was more prone to ankle and knee injury during landing from jump and sprain was most common type of injury and front line position critical zone in volleyball court. This information is useful for team's medical staff for covering the competition and also to design prevention strategies for minimising injury.

\section{INJURIES IN IRANIAN ELITE FEMALE VOLLEYBALL PLAYERS}

Aazam Barani, Nader Rahnama, Effat Bambaeichi Faculty of Physical Education and Sport Sciences, University of Isfahan, Isfahan, Iran

\subsection{6/bjsm.2010.078725.214}

Volleyball is one of the most popular sports in the world. It is the fourth most common source of sports injuries. 